\title{
EFEITO DAS VARIÁVEIS METEOROLÓGICAS SOBRE A FENOLOGIA \\ DE Tipuana tipu (BENTH.) O. KUNTZE NA ARBORIZAÇÃo \\ URBANA DE CURITIBA-PR
}

Kendra Zamproni $^{1}{ }^{2}$, Daniela Biondi ${ }^{3}$, Everaldo Marques de Lima Neto ${ }^{4}$, Angeline Martini ${ }^{5}$

\section{RESUMO}

Esta pesquisa teve por objetivo acompanhar as fenofases reprodutivas e vegetativas de Tipuana tipu (Benth.) O. Kuntze, espécie comumente empregada na arborização das ruas de Curitiba, PR. Selecionou-se 15 exemplares da espécie, sendo cinco em área verde (Jardim Botânico), e os outros 10 exemplares na arborização de ruas (cinco no canteiro central e cinco na calçada). Foram medidas as seguintes variáveis dendrométricas: altura total, circunferência à altura do peito (CAP) e diâmetro de copa. A coleta de dados ocorreu quinzenalmente, durante o período de abril/2010 até março/2011. As variáveis meteorológicas relacionadas com as fenofases foram: temperatura, umidade relativa, precipitação e fotoperíodo. As médias das variáveis dendrométricas das árvores no Jardim Botânico foram as maiores. A queda das folhas nas árvores do canteiro e do Jardim Botânico ocorreu na segunda quinzena de agosto, período coincidente com a ausência de precipitação. Os meses com as maiores médias de temperatura e fotoperíodo correspondem ao período de floração de todas as árvores. As árvores situadas na calçada permaneceram mais tempo com folhas. O início das fenofases reprodutivas e vegetativas não apresentou grandes diferenças entre todas as árvores analisadas. Contudo, pelos resultados obtidos, as variáveis meteorológicas influenciaram no período de duração das diversas fenofases.

Palavras-chave: Ambiente urbano; Fenofases; Temperatura; Precipitação.

\section{EFFECT OF WEATHER VARIABLES ON THE PHENOLOGY OF Tipuana tipu (BENTH.) 0. KUNTZE ON THE URBAN ARBORIZATION OF CURITIBA, PR}

\section{ABSTRACT}

This study aimed to monitor the reproductive and vegetative phenophases of Tipuana tipu (Benth.) O. Kuntze, a species commonly used in trees streets of Curitiba, PR. Fifteen trees of the species were selected, five of them from a green area (Botanical Garden), and other the other ten from the street tree planting (five in the median and five on the sidewalk). The dendrometric variables measured were: height, circumference at breast height (CBH) and canopy diameter. The data were collected fortnightly during the April/2010 to March/2011. The meteorological variables related to the phenophases were: temperature, relative humidity, precipitation and photoperiod. The averages of the dendrometric variables of Botanical Garden's trees were the largest. The fall of the leaves off the trees in the median and the Botanical Garden happened in the second half of august, the period coinciding with the absence of precipitation. The months with the highest average temperature and photoperiod correspond to the blooming period of all trees. The trees on the sidewalk remain longer with leaves. The beginning of the reproductive and vegetative phenophases did not present major differences among all trees analyzed. However, by the results achieved, the meteorological variables had an influence on the duration of the several phenophases.

Key-words: Urban environment; Phenophase; Temperature; Precipitation.

\footnotetext{
${ }^{1}$ recebido em 23.05.2012 e aceito para publicação em 15.06.2013

${ }^{2}$ Curso de Engenharia Florestal da UFPR, Iniciação Científica - CNPq, Curitiba/ PR. kendra.zam@gmail.com

${ }^{3}$ Professora Associada III, Depto. Ciências Florestais, UFPR, Bolsista Produtividade em Pesquisa - CNPq, Curitiba/PR. dbiondi@ufpr.br

${ }^{4}$ Doutorando do Programa em Engenharia Florestal/UFPR, Curitiba/ PR. everaldo.limaneto@gmail.com

${ }^{5}$ Mestranda do Programa em Engenharia Florestal/UFPR. Curitiba/ PR. martini.angeline@gmail.com
} 
Com o rápido e contínuo processo de urbanização, as cidades cresceram de forma desordenada e a vegetação foi negligenciada, assim, o contato com a natureza é cada vez mais raro. Uma alternativa para essa situação é a implantação de áreas verdes e a arborização de ruas nas cidades.

Os ambientes urbanos cada vez mais se tornam objeto de estudos, uma vez que a grande maioria da população mundial vive em áreas urbanizadas profundamente alteradas pela ação antrópica (MATOS et al., 2010). A cidade é o ambiente onde o homem promove seu maior impacto sobre a natureza, portanto é o local onde a paisagem natural é menos preservada (SANCHOTENE, 1999).

Segundo Sucomine e Sales (2010), o ser humano, por muito tempo, conseguiu manter um equilíbrio em suas relações com o ambiente. Contudo, devido ao aumento da população humana e a expansão da industrialização houve um grande fluxo de pessoas do campo para as cidades que, por falta de um planejamento, cresceram desordenadamente, tornando-as ineficientes na promoção de qualidade de vida da população. Diversas pesquisas visando restabelecer o bem-estar outrora perdido consideraram a arborização urbana como um fator essencial para a melhoria dessa qualidade.

A preocupação com o paisagismo e as áreas verdes dentro do ambiente urbano deveria ser tomada como uma prioridade já que estas trazem benefícios psicológicos para a população e amenizam as tão freqüentes situações causadoras de stress (LINHEIRO; BORMANN; LIMA, 1999).

Para Biondi e Althaus (2005) as funções da arborização ainda podem ser vistas segundo valores estéticos, ecológicos, políticos, econômicos e sociais. Os benefícios estéticos referem-se à adição de cores ao cenário urbano com as flores, as folhas e os troncos; à promoção de modelos de paisagens e identidade local, através das espécies; à anulação da monotonia de pavimentos e alvenaria; à introdução de elementos naturais e linhas suaves e orgânicas no meio urbano composto de materiais artificiais e de linhas geométricas; à adição de dinamismo à paisagem urbana através dos aspectos fenológicos como mudança de cor, queda e brotação das folhas, floração e frutificação.

Quanto aos valores ecológicos incluem a captação e/ou retenção de material particulado, adsorção de gases, reciclagem de gases através dos mecanismos fotossintéticos, contribuição para a melhoria da qualidade do ar, redução dos níveis de ruído, diminuição da velocidade dos ventos, equilíbrio ambiental (melhoria microclimática, proteção da avifauna, conforto lumínico) (SANTOS; TEIXEIRA, 2001)

A criação de novas áreas verdes e o aumento de ruas arborizadas eleva consideravelmente a categoria de uma cidade que podem beneficiar os aspectos políticos, sociais e econômicos, principalmente servindo de atração para os turistas (BIONDI; ALTHAUS, 2005). Segundo a Companhia Paranaense de Energia (2011) há, também, valorização de imóveis próximos a áreas arborizadas e redução do consumo de energia em condicionadores de ar, tanto no verão, pela sombra de árvores, quanto no inverno, pela ausência de sombra, no caso de espécies decíduas.

A pesquisa é ferramenta importante para a evolução do planejamento, adequação, implantação e manejo de árvores urbanas. As pesquisas devem contribuir para o estímulo da discussão científica e intelectual 
do presente e do futuro da vegetação urbana de um modo geral (PINHEIRO, 2008).

O padrão de desenvolvimento da vegetação geralmente reflete as condições ambientais. Em um ambiente tão modificado pela ação antrópica, as árvores possivelmente irão reagir de modo diferente do seu habitat natural. O meio urbano é complexo e ainda pouco estudado do ponto de vista ecológico. Conhecê-lo significa compreender essas mudanças. Os estudos fenológicos propiciam a visualização das possíveis diferenças que os efeitos meteorológicos causam nas atividades biológicas dos seres vivos e, a partir disso, inferir como o mesmo reage ao meio em que se encontra.

Segundo Prause e Angeloni (2000), a fenologia é um ramo da ecologia que estuda os fenômenos periódicos dos seres vivos e suas relações com as condições ambientais, tais como temperatura, luz, precipitação, etc. O registro da atividade biológica visível dos organismos serve para interpretar a reação dos mesmos com o complexo climático do lugar.

A habilidade das plantas e animais de detectar as variações do ambiente, como o comprimento relativo dos dias e das noites e as variações de temperatura, permite que um determinado evento ocorra em uma época particular do ano, constituindo, portanto uma resposta sazonal (KERBAUY, 2004).

O conhecimento da fenologia é baseado nas observações de estádios de desenvolvimento externamente visíveis (fenofases), como, por exemplo, a germinação de sementes, emergência das gemas, desenvolvimento das folhas, floração, senescência (LARCHER, 2006).

Conforme Palioto et al. (2007) a fenologia é pouco conhecida para muitas espécies cultivadas fora de sua área natural.
De uma maneira geral, os estudos sobre fenologia de espécies arbóreas em áreas florestais são necessários para fornecer parâmetros com vistas à conservação e exploração racional, conciliando sustentabilidade com economicidade (MELLINGER; RICHERS 2005).

Schubert (1979) afirma que cada espécie vegetal é dependente de condições ambientais favoráveis à sua sobrevivência e, além disso, ao seu adequado desenvolvimento. As exigências de uma espécie, variáveis em termos de condições climáticas e edáficas em interação, apresentam-se em níveis de limites mínimos e máximos, dentro dos quais se estabelecem faixas de valores ou características para um ótimo desenvolvimento biológico de cada espécie.

Na arborização urbana, o conhecimento fenológico das espécies vegetais componentes, que sempre vivem sob algum nível de estresse fisiológico, pode indicar, de acordo com o seu ritmo de fenofases em situação natural, a presença ou ausência de regularidade no mesmo e, neste último caso, ser base para o planejamento de ações silviculturais que permitam uma melhor adaptação das espécies ao ambiente urbano (BRUN et al., 2007).

De acordo com Martini (2011), é com base em informações referentes à estudos de desenvolvimento das plantas em seu meio naturalflorestas ou remanescentes florestais- que muitos planejadores da arborização urbana se fundamentam. Entretanto, o conhecimento sobre o seu desenvolvimento natural não é suficiente para garantir a eficiência da utilização de uma espécie no meio urbano, onde as condições são muito distintas. Ainda afirma que os estudos fenológicos são uma ferramenta de grande importância para o planejamento e manutenção da arborização urbana. Saber a época e duração das fenofases das plantas

EFEITO DAS VARIÁVEIS METEOROLÓGICAS... 
no meio onde estão inseridas, bem como os fatores que afetam seu comportamento, permite a readequação deste patrimônio público. O que proporciona menores custos e melhor aplicação do recurso humano especializado, de maneira a melhorar e aperfeiçoar a gestão.

Dentro deste contexto, o presente estudo teve como principal objetivo avaliar o comportamento fenológico de Tipuana tipu (Benth.) O. Kuntze, árvore amplamente empregada na arborização de ruas da cidade de Curitiba. Além de entender o efeito das variáveis meteorológicas sobre as diversas fenofases da espécie, também foi ponderado se existem diferenças fenológicas nas diferentes formas de ocorrência da espécie na arborização urbana.

\section{MATERIAIS E MÉTODOS}

\section{Descrição da área de estudo}

O município de Curitiba localiza-se no Primeiro Planalto a uma altitude média de 934,6 m acima do nível do mar (IPPUC, 2006) e situa-se a 2543’ de latitude sul e $49^{\circ} 27^{\prime}$ de longitude oeste (INPE, 2008), conforme Figura 1.

Segundo a classificação de Köppen, a capital paranaense localiza-se em região climática do tipo Cfb, com clima subtropical úmido, mesotérmico, sem estação seca, com verões frescos e invernos com geadas freqüentes e ocasionais precipitação de neve. Conforme estudo realizado pelo IPPUC entre os anos de 1998 e 2008, Curitiba apresentou temperatura média máxima de $21,29^{\circ} \mathrm{C}$ (no mês de fevereiro) e média mínima de $13,78^{\circ} \mathrm{C}$ (em julho). A precipitação média, de acordo com o mesmo instituto nos anos de 1998 a 2010(outubro) foi de $1385,35 \mathrm{~mm}$.

Figura 1. Localização da área de estudo

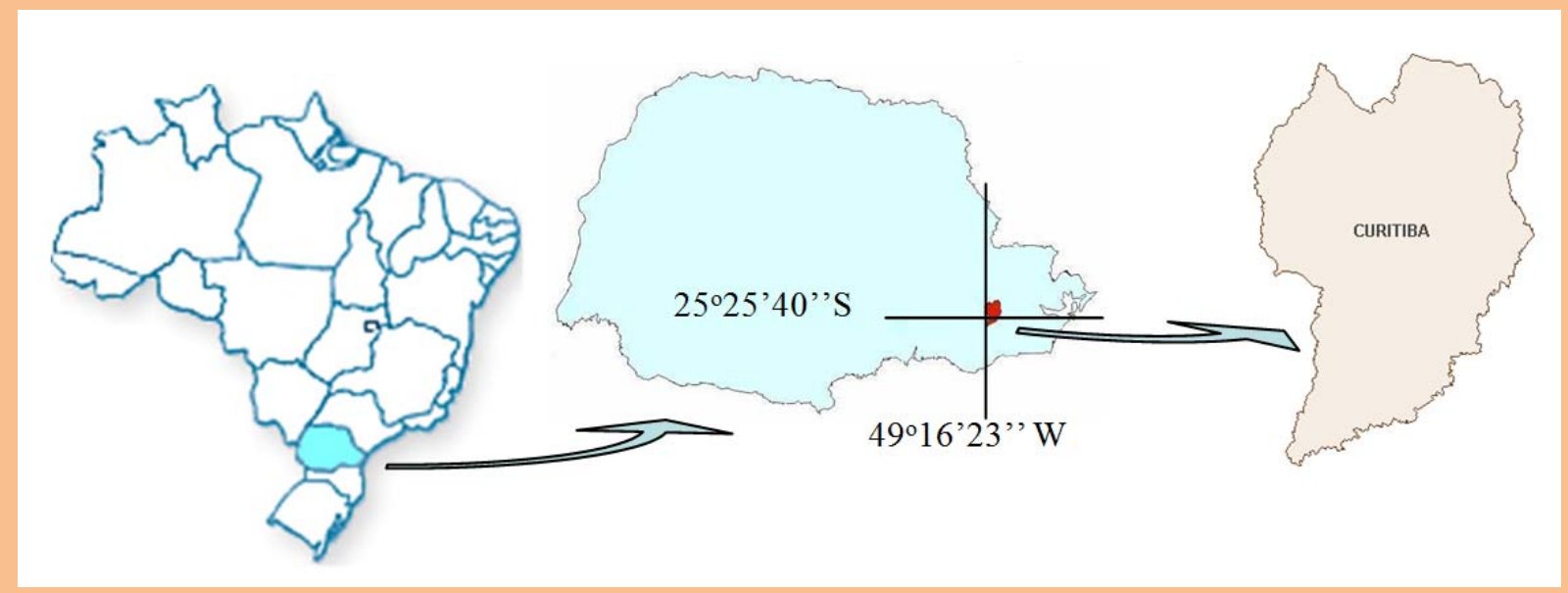

Fonte: Vieira (2006).

Kendra Zamproni et al. 
Este trabalho foi realizado nas proximidades do Campus III da Universidade Federal do Paraná
(Figura 2). Mais precisamente na Rua Dr. Jorge Meyer Filho, bairro Jardim Botânico, Curitiba-PR.

Figura 3. Croqui da área de estudo

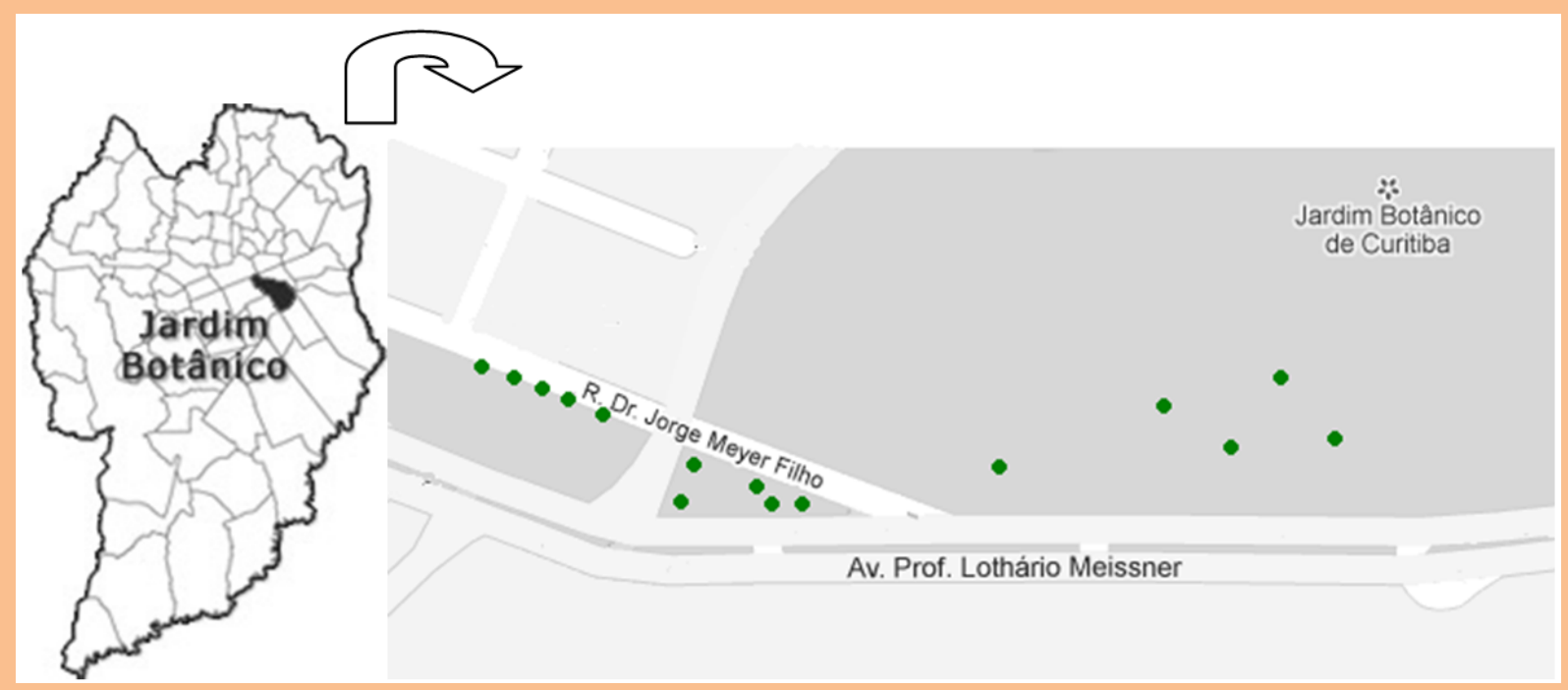

Fonte: Adaptado de IPPUC (2011)

\section{Descrição e características da espécie estudada}

Tipuana tipu (Benth.) O. Kuntze é uma espécie de origem sul americana, mais precisamente da Bolívia, Argentina e sul do Brasil. (BIONDI; ALTHAUS, 2005).

De acordo com Biondi e Althaus (2005) essa é uma árvore de grande porte (pode passar de 20 metros de altura) e caducifólia, porém o grau de desfolhamento depende da intensidade da estiagem. A casca é rugosa e saliente, sulcada longitudinalmente (LORENZI et al., 2003). As folhas são alternas, compostas, imparipinadas, com 4 a 11 pares de folíolos oblongos e margem inteira. As inflorescências são axilares, em racemos, compostas por flores amarelas com estrias vermelhas (BACKES; IRGANG, 2004). O fruto é do tipo sâmara, indeiscente, geralmente com uma ou duas sementes (BIONDI; ALTHAUS, 2005). Lorenzi et al. (2003) afirma que o grande destaque dessa árvore é a copa densa e frondosa, formada por ramos recurvados.

Segundo Backes e Irgang (2004) a floração ocorre na primavera/verão e a frutificação no inverno. Para Biondi e Althaus (2005), a floração ocorre de novembro a março e a frutificação de abril a agosto. A espécie apresenta rápido crescimento e boa tolerância a condições adversas (LORENZI et al., 2003). É pouco exigente, podendo se desenvolver em solos compactados e secos (BIONDI; ALTHAUS, 2005).

A tipuana é uma das Leguminosas mais empregadas na arborização urbana de Curitiba e é considerada uma das árvores mais cultivadas nas 
cidades do sul do Brasil. Os ramos divergentes e tortuosos formam enormes copas, que em ruas estreitas formam túneis verdes. Destaca-se a intensa floração, cobrindo as ruas e calçadas com pétalas

\section{Procedimentos metodológicos}

Para estudos fenológicos, Ramalho (1976), recomenda 3 indivíduos de cada espécie para ambientes florestais. Como não existem pesquisas de fenologia em ambientes urbanos, foram selecionados 15 exemplares da espécie Tipuana tipu (Benth.) O. Kuntze pertencente a família Fabaceae, subfamília Papilionoideae (ou Faboideae).

Para avaliar a fenologia nas diferentes formas de ocorrências na arborização urbana, os 15 exemplares foram distribuídos em três maneiras (Figura 2). Cinco destas árvores estão situadas dentro de uma área verde - o Jardim Botânico, em Curitiba. Estas crescem livremente, em local aberto com forração de grama e não há concorrência coloridas e os frutos alados que se dispersam pelo vento (BACKES; IRGANG，2004; BIONDI; ALTHAUS, 2005). expressiva com elementos urbanos, cinco árvores encontram-se no canteiro central entre as ruas Prof. Lothário Meissner e Dr. Jorge Meyer Filho. Essas árvores também estão em local com canteiro coberto com grama, porém há contato direto com a poluição dos automóveis e são limitadas pela pavimentação e pelo asfalto. As demais se localizam na calçada da rua Dr. Jorge Meyer Filho. Nesse local a área com permeabilidade em torno das árvores é mínima e, além do asfalto e da pavimentação, também há a interferência das construções (Figura 3).

Figura 3. Tipuana tipu nas diferentes formas de ocorrência na arborização urbana

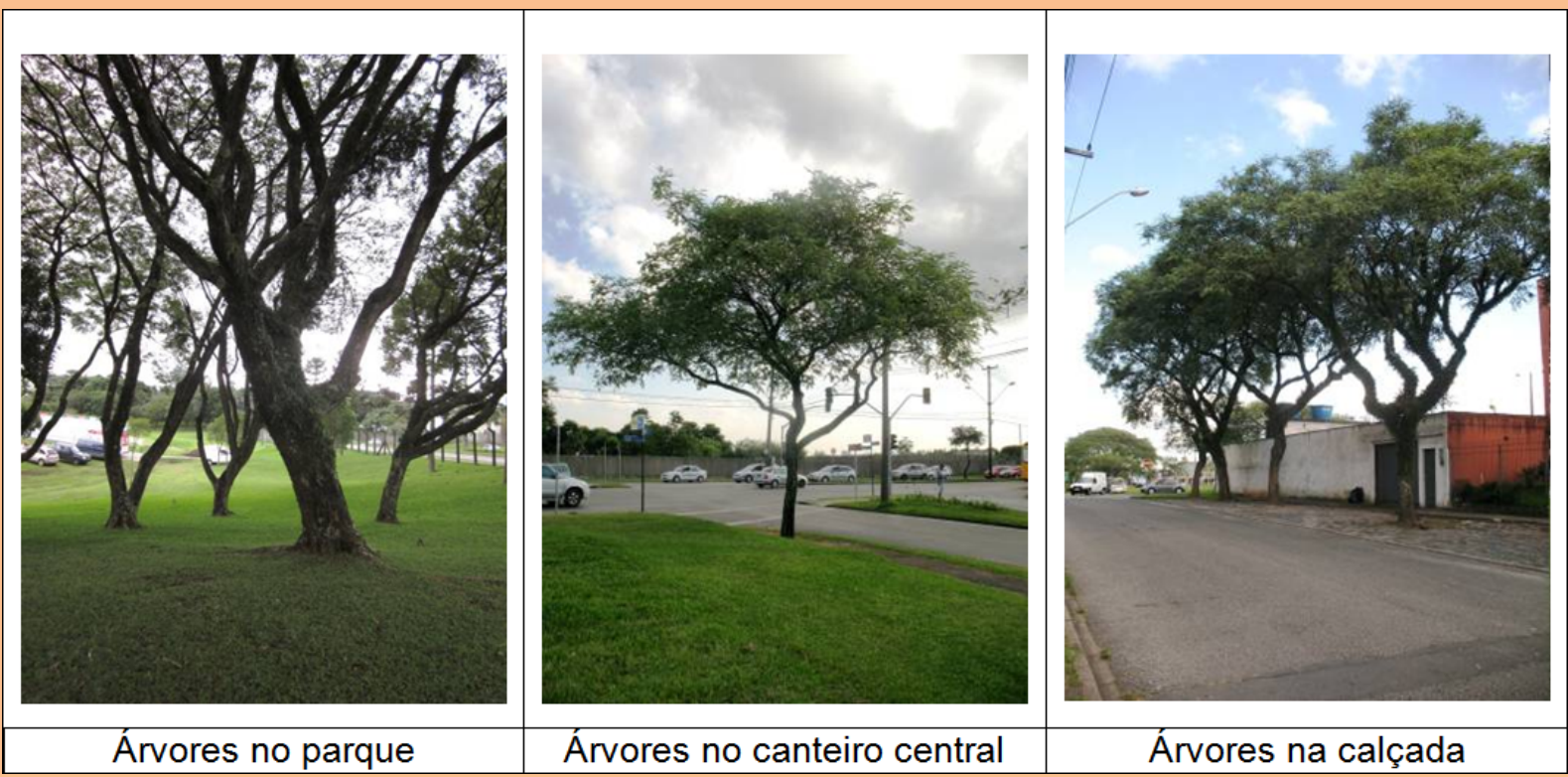

Kendra Zamproni et al. 
Em todos os quinze indivíduos foram medidas as seguintes variáveis dendrométricas: CAP (cm), altura total (m), diâmetro de copa (sentido rua e sentido calçada- em metros). Nas árvores estabelecidas na calçada, foi realizada a medição da distância entre a árvore e o meio-fio. Para aquelas que se situam no canteiro, foi medido o tamanho do mesmo. Também foi avaliada a presença ou não de epífitas e foram relatas demais observações relevantes (como a presença de erva de passarinho). O estudo fenológico foi de caráter qualitativo e foram observadas características reprodutivas e vegetativas. A coleta de dados ocorreu quinzenalmente, através da observação in loco, durante o período de abril/2010 até março/2011. Quanto ao período reprodutivo foram observadas as fenofases de floração com botões florais, flores abertas e floração terminada e frutificação com frutos verdes, frutos maduros e frutos caindo. Referente ao período vegetativo usou-se o seguinte critério: folhas novas, maioria de folhas novas, maioria de folhas velhas e desfolhada (Figura 4). A determinação de cada fenofase foi feita através de sua predominância no período observado.

Figura 4. Fenofases reprodutivas e vegetativas de Tipuana tipu

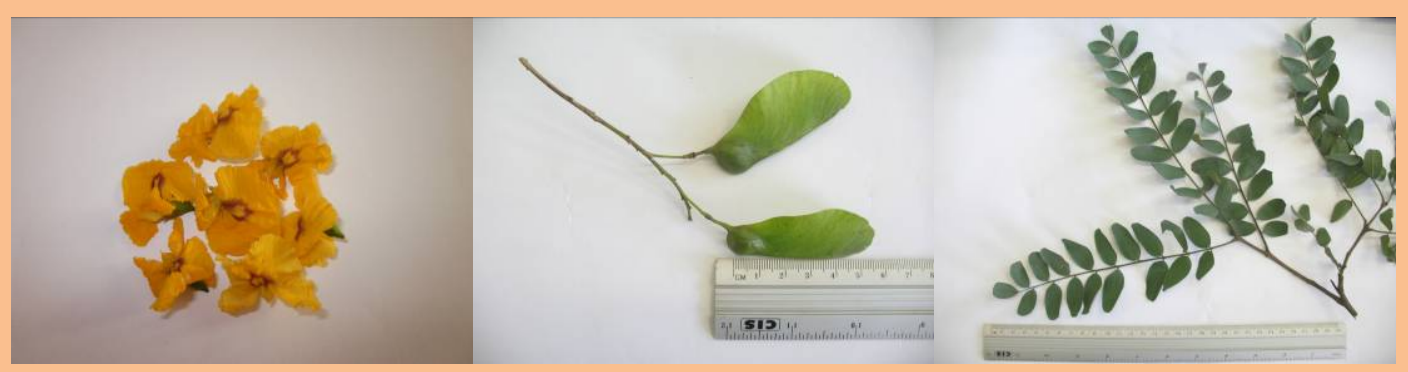

Por fim, as fenofases das plantas foram correlacionadas com dados meteorológicos obtidos junto ao Instituto SIMEPAR, situado aproximadamente a $1,5 \mathrm{Km}$ do local de estudo.
Estes dados, obtidos e processados quinzenalmente, foram: valores médios diários de temperatura $\left({ }^{\circ} \mathrm{C}\right)$, umidade relativa do ar (\%) e os valores totais diários de precipitação (mm) e fotoperíodo (h).

\section{RESULTADOS E DISCUSSÃO}

\section{Características dendrométricas das árvores analisadas}

A Figura 5 ilustra as médias das variáveis dendrométricas medidas em campo. Observa-se que as árvores situadas dentro da área verde (Jardim Botânico) possuem as maiores médias de CAP $(184,8 \mathrm{~cm})$, altura total $(12,6 \mathrm{~m})$ e diâmetro de copa (16,33 m). Segundo Biondi e Althaus (2005), as árvores adultas desta espécie possuem de 10 a 15 metros de altura. Todas as árvores desde estudo enquadram-se nesta descrição, logo elas estão no período de maturidade.

Nota-se na Figura 5, que os indivíduos presentes na arborização de ruas (calçada e canteiro) apresentaram dimensões bem inferiores às da área verde, o que pode ser explicado pelas condições do solo. Segundo Milano e Dalcin (2000), as árvores

EFEITO DAS VARIÁVEIS METEOROLÓGICAS... 
nas cidades, submetidas à compactação do solo, tem um pequeno crescimento.

A área do canteiro entre as ruas Prof. Lothário

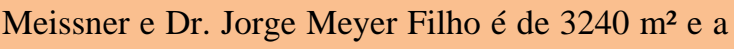
distância das árvores da calçada até o meio-fio é de 2,5 m. Em todas as árvores (100\%) da calçada e da área verde (Jardim Botânico de Curitiba) e em 60\% das árvores do canteiro foi constatado a presença de epífitas. Em 20\% dos indivíduos da calçada e do canteiro há problemas com erva-de-passarinho. Isso também acontece em 60\% das árvores da área verde.

Figura 5. Média das variáveis dendrométricas dos indivíduos de Tipuana tipu
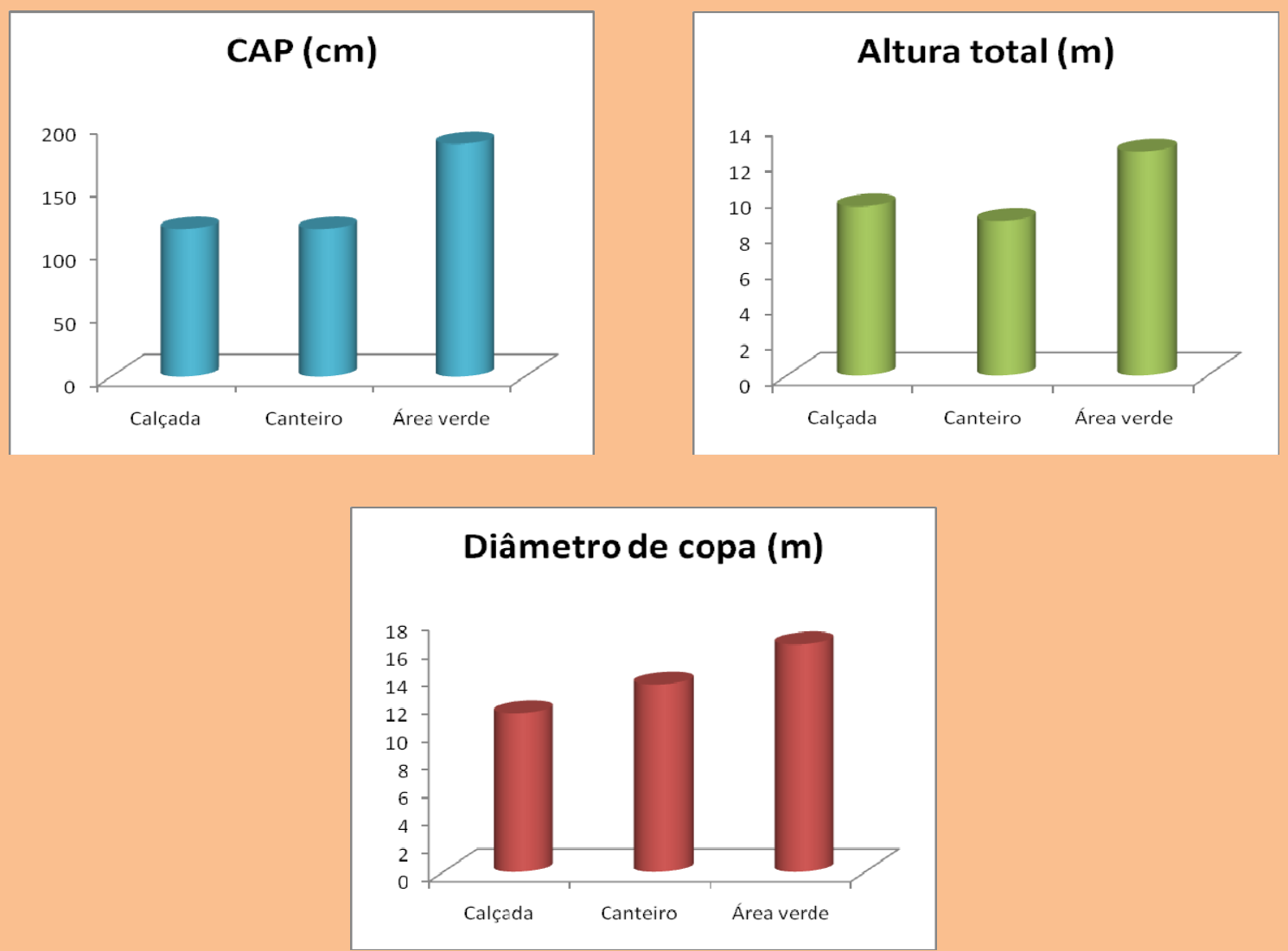

\section{Padrões das fenofases}

Conforme a Figura 6, observa-se que na maioria dos meses do ano as árvores permaneceram com folhas (em geral 9 meses). A queda da folhagem daquelas situadas na calçada ocorreu na primeira quinzena de setembro e elas permaneceram todo esse mês sem folhas (Figura 7). As árvores localizadas nesse ambiente permaneceram com folhas quinze dias a mais que as demais árvores. A queda foliar dos indivíduos do canteiro e do Jardim Botânico ocorreu na mesma época (segunda quinzena de agosto). A brotação das folhas de todas as árvores começou na primeira metade do mês de outubro e um mês depois todos os indivíduos já possuiam folhas adultas. Em um estudo fenológico 
realizado por Brun et al. (2007), com exemplares desta mesma espécie empregados na arborização de ruas em Santa Maria (RS), o autor observou um período de seis meses sem folhas, o que é distinto do resultado obtido no presente estudo.

Figura 6. Fenofases das espécies selecionadas

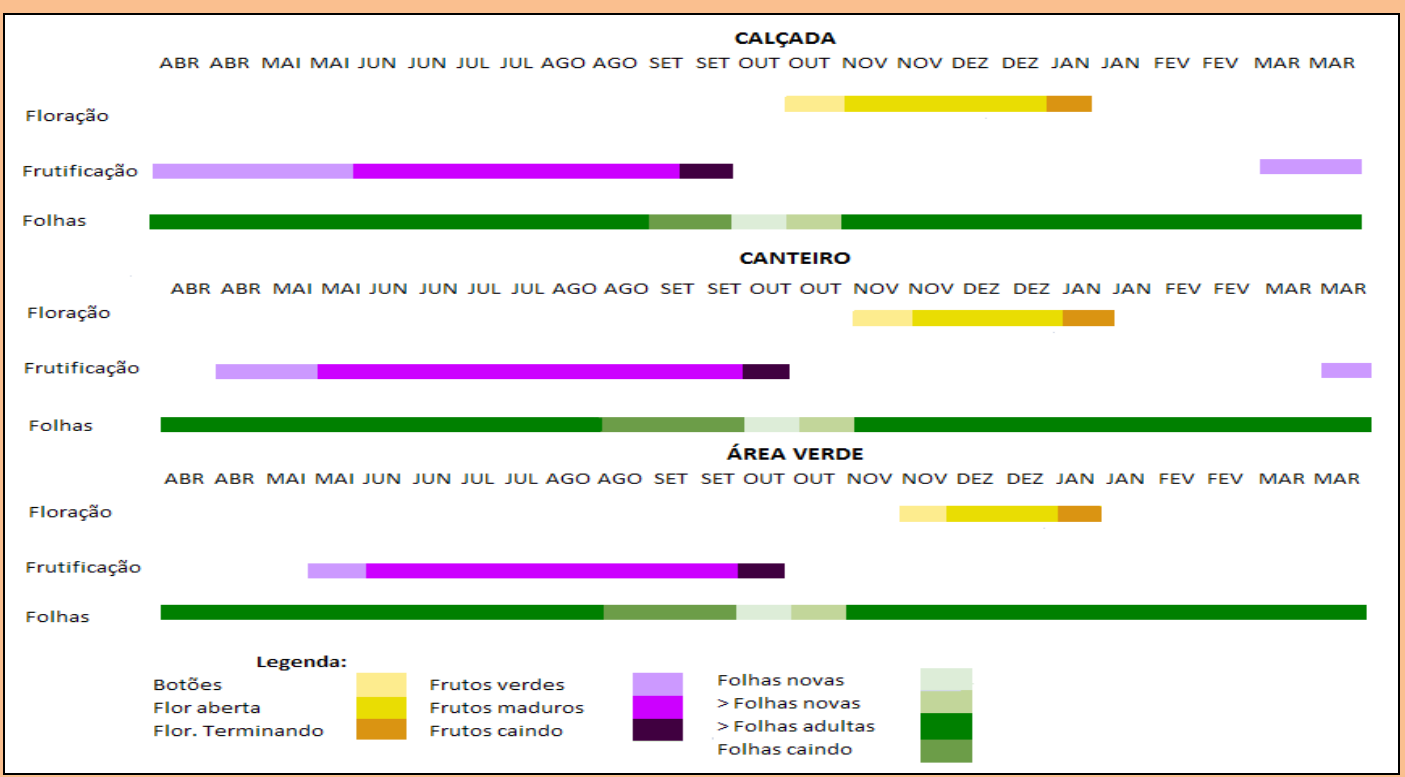

$\mathrm{O}$ ato de varrer as folhas das calçadas, de acordo com Biondi, Reissmann e Batista (1999), faz com que elementos como $\mathrm{Ca}, \mathrm{Mg}, \mathrm{Fe}, \mathrm{Mn}, \mathrm{Cu}$ e $\mathrm{Al}$ deixem de ser incorporados ao solo, podendo haver deficiências de micronutrientes pela quebra no processo da ciclagem natural dos elementos. Este processo pode ser responsável pelas diferenças fenológicas observadas.

Figura 7.Queda foliar de Tipuana tipu

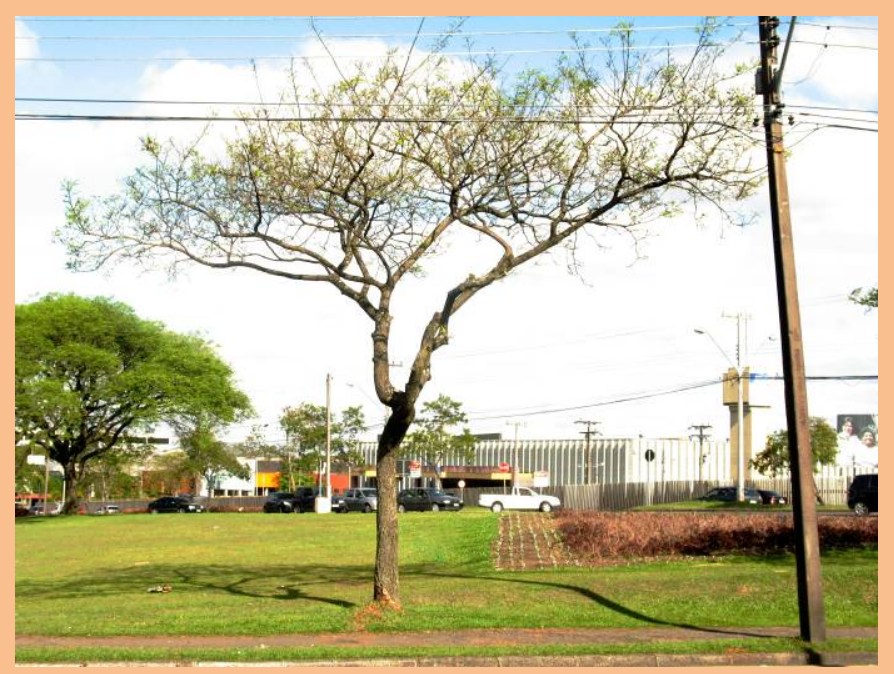

EFEITO DAS VARIÁVEIS METEOROLÓGICAS...

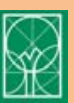


Com relação as flores (Figura 8) percebe-se que o surgimento destas nos indivíduos da calçada iniciou quinze dias antes das plantadas do canteiro central e um mês antes das encontardas na área verde. Os exemplares plantados na calçada permaneram mais tempo com flores abertas e os da área verde (Jardim Botânico) apresentaram um curto período de floração. Em todos os ambientes a floração se encerrou na primeira quinzena de janeiro.

Figura 8. Floração de Tipuana tipu

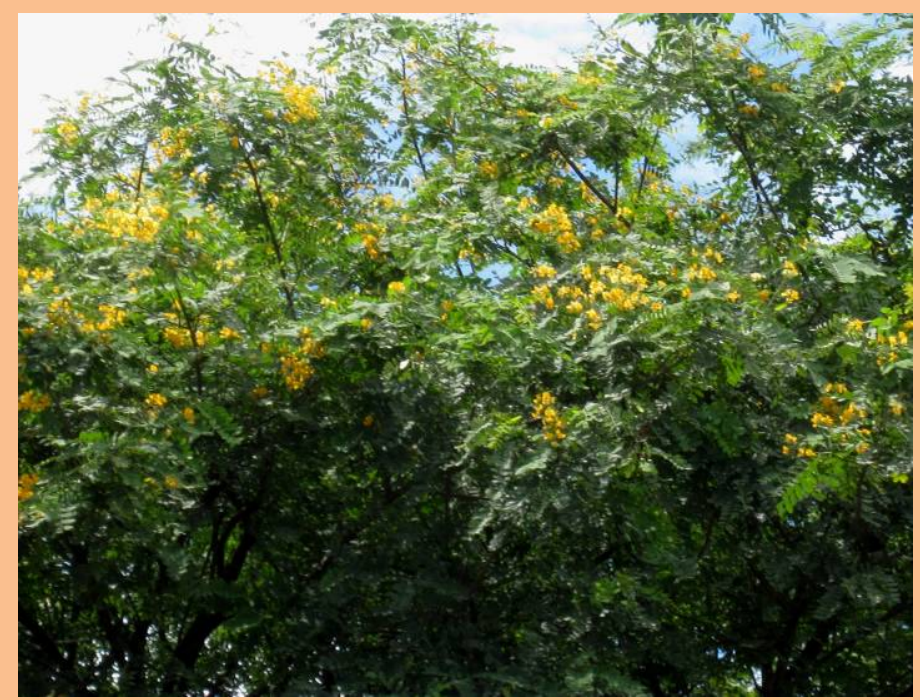

Observa-se na Figura 6 que o período de floração condiz com Biondi e Althaus (2005), apenas os indivíduos plantados na calçada iniciaram este período mais cedo. O período de floração ainda é similar ao encontrado por Brun et al. (2007), em Santa Maria (RS).

Há um significativo atraso no surgimento de frutos nas espécies situadas na área verde com relação às da calçada. E enquanto as árvores dos outros dois ambientes já possuiam frutos verdes ao final da coleta de dados, as da área verde ainda não estava no período de frutificação. A maturação dos frutos nos indivíduos do canteiro foi mais rápida que a dos demais ambientes e por quatro meses e meio foi possível observar a presença de frutos maduros. As árvores da calçada foram as que apresentaram menor tempo de permanência desses frutos. No estudo fenológico, anteriomente citado, realizado por Brun et al. (2007), o período de frutificação não condiz com encontrado neste estudo, em Santa Maria a frutificação ocorreu nos meses de dezembro a julho. Há também disparidade entre os dados encontrados e os apostados por Biondi e Althaus (2005).

Conforme Martini (2011), as espécies podem apresentar um período mais longo de floração no meio urbano, o que a torna mais interessante para a população, porém a intensidade da florada pode ser menos expressiva. O que acarretará mudanças também na frutificação. Os frutos podem demorar mais tempo para se formar e se disseminarem por um período menor de tempo. Ou ainda, a perda de folhas pode acontecer em um período curto e a árvore desfolhada permanece por mais tempo nas ruas.

Kendra Zamproni et al. 
Os resultados obtidos nesse estudo possuem certa semelhança com o que com Backes e Irgang (2004) afirmam. De acordo com os autores, a Tipuana tipu,

\section{Comportamento meteorológico}

Na figura 7 é apresentado o comportamento das variáveis meteorológicas distribuídos em meio natural, floresce na primavera e no verão e a frutificação ocorre no inverno. quinzenalmente entre abril de 2010 e março de 2011.

Figura 7. Comportamento das variáveis meteorológicas: Temperatura média (A); Umidade Relativa (B); Precipitação (C); Fotoperíodo (D) por quinzena nos anos 2010 e 2011.

A)

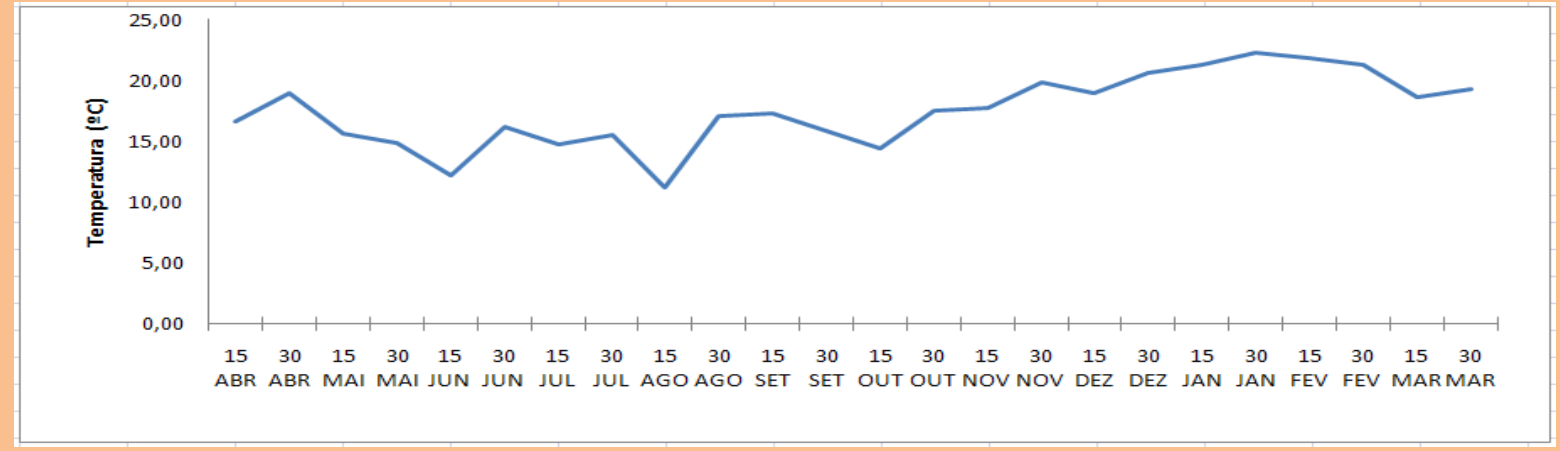

B)

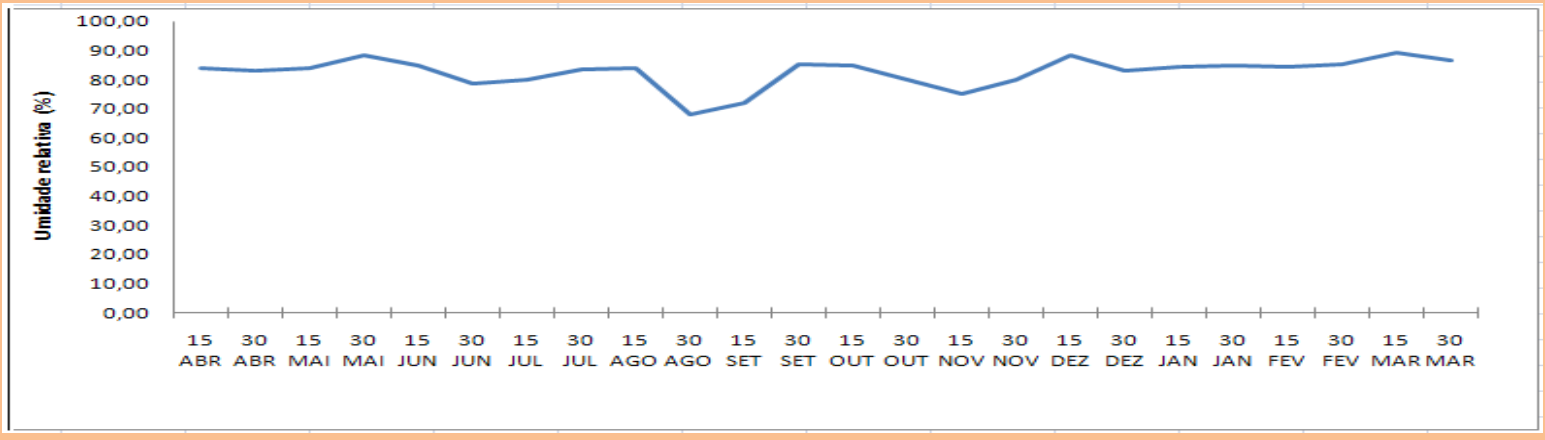

C)

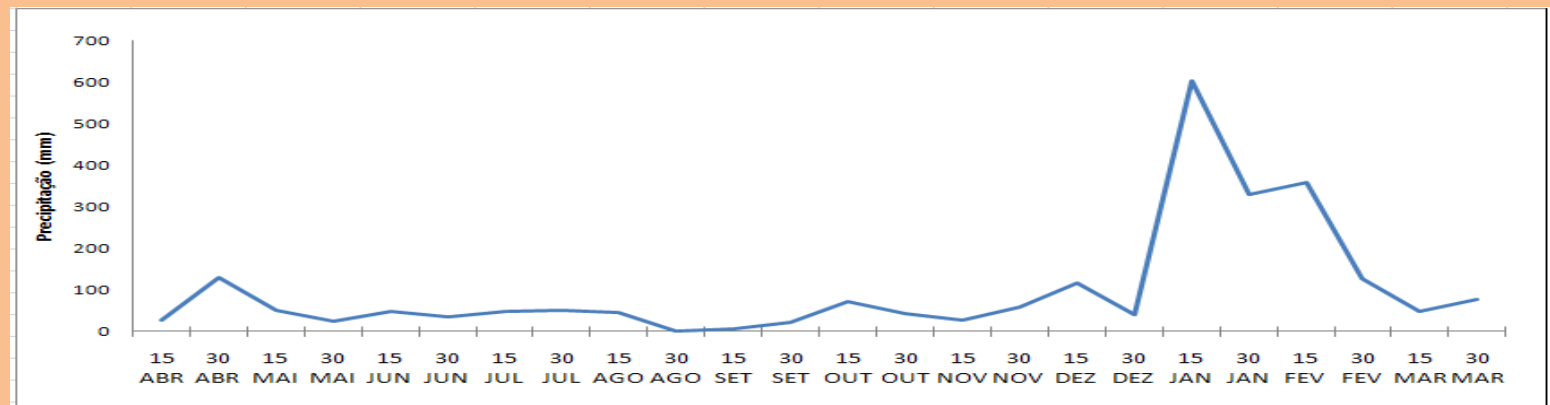


D)

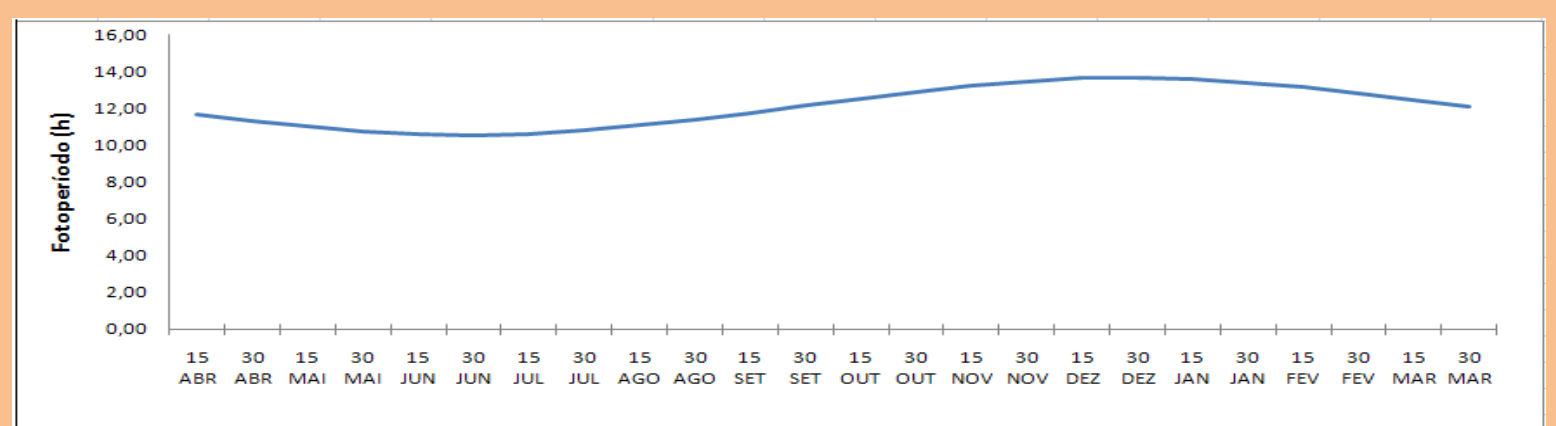

A maior média de temperatura $\left(22,29^{\circ} \mathrm{C}\right)$ ocorreu na segunda metade de janeiro e a menor $\left(11,19^{\circ} \mathrm{C}\right)$ na primeira quinzena de agosto. O período com maior umidade relativa ocorreu na primeira metade do mês de março, com 89,03\% e o menor valor (67,8 \%) dessa variável aconteceu na segunda quinzena de agosto, período que coincidiu também com a ausência de precipitação. A precipitação atingiu seu máximo na primeira metade do mês de janeiro (603,4mm). O mínimo de fotoperíodo ocorreu na segunda quinzena de julho (10,53 h) e seu máximo na segunda quinzena de dezembro (13,69 h).

Observa-se que a temperatura média atingiu seu menor valor $\left(11,19^{\circ} \mathrm{C}\right)$ na primeira metade de agosto, logo após ocorre a queda foliar nas árvores situadas no canteiro central e na área verde. A perda da folhagem também coincide com o período de ausência de precipitação ocorrido na segunda quinzena desse mesmo mês. Segundo Larcher (2006) o sinal para a senescência é frequentemente originado por fatores externos, como dias curtos e ocorrência de certos limites de temperatura.

Percebe-se que quando a temperatura média começa a aumentar em outubro, surgem os primeiros botões florais e a floração já está terminada quando a temperatura atinge seu auge na segunda quinzena de janeiro. O período de floração também coincide com os meses de maiores índices de fotoperíodo. Ainda pode-se observar que a queda das flores inicia no mesmo período que a precipitação atinge seu índice mais elevado (358,20 $\mathrm{mm})$. Kozlowski (1985), afirma que de modo geral a época de formação de flores das árvores em qualquer espécie parece, sobretudo ser controlada pela temperatura. Esta é responsável também pela regulação da produção de sementes e frutos, iniciação floral, dormência dos botões, abertura de flores e abertura e crescimento dos frutos.

Martini (2011) afirma que as variáveis meteorológicas estabelecem condições para o desenvolvimento das plantas e impõem limites para sua existência. Elas podem controlar a época de surgimento de uma fenofase e ainda influenciar na duração e intensidade desta.

Não é uma tarefa fácil avaliar os fatores climáticos responsáveis pelo desencadeamento dos fenômenos fenológicos, pois o impulso efetivo, como, por exemplo, a passagem de um limite de temperatura, é modificado por um grande número de condições internas e externas da planta (LARCHER, 2006). 
O início das fenofases reprodutivas e vegetativas apresentou diferenças principalmente entre as árvores situadas na área verde e as situadas na calçada, portanto pode-se inferir que o local em que as árvores foram plantadas interferiu na fenologia das mesmas. Pelos resultados obtidos, as variáveis meteorológicas também influenciaram no período de duração das diversas fenofases.
É importante ressaltar que os resultados desse estudo, com relação às características fenológicas e o comportamento das variáveis meteorológicas, restringem-se ao período analisado e ao local de estudo. Dessa forma, recomenda-se a continuação do estudo por um período maior e em outros locais da cidade para reforçar os resultados.

\section{REFERÊNCIAS BIBLIOGRÁFICAS}

BACKES, P.; IRANG, B. Árvores Cultivadas no sul do Brasil - Guia de Identificação e Interesse paisagístico das principais espécies exóticas. Porto Alegre: Paisagens do Sul, 2004.

BIONDI, D.; ALTHAUS, M. Árvores de Rua de Curitiba- Cultivo e Manejo. Curitiba: FUPEF, 2005.

BIONDI, D.; REISSMANN, C. B.; BATISTA, A. C. Exportação de nutrientes devido a varrição

das folhas de Acer negundo L. plantado nas ruas de Curitiba-PR. In: 50 Congresso Nacional

de Botânica, 1999, Blumenau. Anais... Blumenau: SBB-FURB-UFSC-UNESC-HBREPAGRI,. v. 1. 1999. p. 103.

BRUN, F.G.K, LONGHI, S.J.; BRUN, E.J.; FREITAG, A.S.; SCHUMACHER, M.V. Comportamento fenológico e efeito da poda em algumas espécies empregadas na arborização do bairro Camobi - Santa Maria, RS. Revista da Sociedade Brasileira de Arborização Urbana. Piracicaba, v.2, n.1, p. 44-63, 2007.

COMPANHIA PARANAENSE DE ENERGIA - COPEL. Arborização de vias públicas. Disponível em: < http://www.copel.com/hpcopel/guia_arb/a_arborizacao_urbana.html>. Acesso em: 06 jul. 2011.

INSTITUTO DE PESQUISA E PLANEJAMENTO DE CURTIBA - IPPUC. Curitiba em Dados. Disponível em:

http://www.ippuc.org.br/Bancodedados/Curitibaemdados/anexos/Hist\%C3\%B3rico\%20dos\%20Parques\%20e\%2 0Bosques.pdf

INSTITUTO NACIONAL DE PESQUISAS ESPACIAIS -INPE. Meteorologia. Disponível em: <http://tempo.cptec.inpe.br:8080/prevnum/buscaMeteo.jsp?action=1\&modelo=Eta20\&cidade=curitiba\#>. Acesso em: 06 jul. 2011.

KERBAUY,G.B. Fisiologia Vegetal. Rio de Janeiro: Guanabara Kooggan, 2004. 
KOZLOWSKI, T.T. Soil aeration, flooding, and tree growth. Journal of Arboriculture, v. 11, n.3, p. 85-96, 1985.

LARCHER, W. Ecologia vegetal. São Carlos: Rima, 2006.

LINHEIRO, M.E.V., BORMANN, N.P., LIMA, P.R.C. Paisagem em cidades: uma ação comunitária. In: VIII ENCONTRO NACIONAL DE ARBORIZAÇÃO URBANA.p 43-46. Anais...Fortaleza, 1999.

LORENZI,H.; SOUZA, H.M., TORRES, M.A.V., BACHER, L.B. Árvores exóticas no Brasil - madeireiras, ornamentais e aromáticas. Nova Odessa, SP: Instituto Plantarum, 2003.

MARTINI, A. Estudos Fenológicos em Árvores de Ruas. In: Pesquisa em arborização de ruas. Curitiba: O Autor, 2011. Cap. 2, p. 29- 45.

MATOS, E.C.A; NASCIMENTO-JÚNIOR, J.E; MARIANO, D.L.S; OLIVEIRA, A.L. Arborização do bairro centro da cidade de Aracaju, Sergipe, e seus organismos associados. Revista da Sociedade Brasileira de Arborização Urbana. Piracicaba, v.5, n.4, p.22-39, 2010.

MELLINGER, L. L.; RICHERS, B. T. Fenologia de espécies oleaginosas na rds Amanã, Maraã (AM) dados parciais. 2005. Disponível em: <http://www.mamiraua.org.br/arq/Mellinger\&Richers-

FenologiaOleaginosasAmana-SAPII.pdf>. Acesso em: 6 jul. 2011.

MILANO, M.; DALCIN, E. Arborização de Vias Públicas. Rio de Janeiro: Light, 2000.

PALIOTO, G.F. et al. Fenologia de espécies arbóreas no campus da Universidade Estadual de Maringá-PR. Revista brasileira de Biociências. 2007. Disponível em:

<http://www6.ufrgs.br/seerbio/ojs/index.php/rbb/issue/view/22/showToc> . Acesso em: 01 ago. 2011.

PINHEIRO, J.A.N. Arborização Urbana. 2008. Disponível em:<

http://www.webartigos.com/articles/9812/1/Arborizacao- Urbana/pagina1. html\#ixzz1GmvUKMEz >. Acesso em: 06 jul. 2011.

PRAUSE, J.; ANGELONI, P. Fenología de especies forestales nativas: abscisión de hojas. Universidad Nacional del Nordeste: Comunicaciones Científicas y Tecnológicas. 2000. Disponível em: <

http://www.unne.edu.ar/Web/cyt/cyt/2000/5_agrarias/a_pdf/a_058.pdf >. Acesso em: 06 jul. 2011.

RAMALHO, R. S. Dendrologia. v.1. Viçosa: UFV, 1976. 123p.

SANCHONETE, M.C. A arborização urbana como parte integrante da paisagem. In: VIII ENCONTRO NACIONAL DE ARBORIZAÇÃO URBANA. Anais...p. 50-52 Fortaleza, 1999.

SANTOS, N.R.Z. ; TEIXEIRA, I.F. Arborização de Vias Públicas: ambiente X vegetação. Santa Cruz do Sul: Instituto Souza Cruz, 2001.

SCHUBERT, T.H. Trees for urban use in Puerto Rico and The Virgin Islands. Rio Piedras, Porto Rico: USDA Forest Service, 91p. 1979.

SUCOMINE, N.V., SALES, A. Caracterização e análise do patrimônio arbóreo da malha viária urbana central do município de São Carlos-SP. Revista da Sociedade Brasileira de Arborização Urbana. Piracicaba, v.5, n.4, p.128-140, 2010.

VIEIRA, C. H. S. D. Estudo da dinâmica de cobertura vegetal de Curitiba-Pr com uso de imagens digitais. 2006. Dissertação (Mestrado em Engenharia Florestal), Setor de Ciências Agrárias, Universidade Federal do Paraná. $152 f$.

Kendra Zamproni et al. 